\title{
Nonlinear Dynamics of Seismicity and Fault Zone Dynamics Around Large Dams: The Case of Enguri Dam, Caucasus ${ }^{+}$
}

\author{
Tamaz Chelidze *, Teimuraz Matcharashvili, Vakhtang Abashidze, Nadezhda Dovgal, \\ Ekaterine Mepharidze and Lia Chelidze \\ M. Nodia Institute of Geophysics, Tbilisi State University, 0160 Tbilisi, Georgia; \\ Matcharashvili@gtu.ge (T.M.); abash_geo@hotmail.com (V.A.); dovgalnadya@yahoo.com (N.D.); \\ ekamep@gmail.com (E.M.); lia.chelidze@gmail.com (L.C.) \\ * Correspondence: tamaz.chelidze@gmail.com \\ + Presented at the 2nd International Electronic Conference on Geosciences, 8-15 June 2019; \\ Available online: https://iecg2019.sciforum.net/.
}

Published: 26 December 2019

\begin{abstract}
The $271 \mathrm{~m}$ high Enguri arch dam, still one of the highest arch dams in operation in the world, was built in the canyon of the Enguri river (West Georgia) in the 1970s. It is located in a zone of high seismicity (MSK intensity IX) and close to the Ingirishi active fault. The high seismic and geodynamical activities together with the large number of people living downstream of the dam make the Enguri dam a potential source of a major catastrophe in Georgia. Thus, the Enguri Dam with its 1 billion cubic meter water reservoir should be under permanent monitoring. At the same time, this area is an amazing natural laboratory, where one can investigate both tectonic and geotechnical strains and processes as well as their response to the lake load-unload impact (i.e., the reaction to a controllable loading of the Earth crust). This is an important scientific issue, connected with a fundamental problem of reservoir-induced earthquakes as well as with environmental geotechnical problems related to the safety of large dams. Application of nonlinear dynamics methods allows for the division of events, ordered by reservoir water regular strain impact from the background seismicity.
\end{abstract}

Keywords: large dams; large dams; nonlinear dynamics; fault zone strain; triggered seismicity; (List three to ten pertinent keywords specific to the article; yet reasonably common within the subject discipline)

\section{Introduction}

Monitoring of strains and seismic activity in the area of a large dam is a unique tool for understanding the intimate connections between earthquake generation and man-made regular quasi-periodic strains in the Earth created by seasonal water load-unload in the reservoir. We can consider the area of large dams as a natural laboratory, providing the possibility of studying the seismic process in almost controlled (repeated) conditions.

The $271 \mathrm{~m}$ high Enguri arc dam (still one of the largest in the world) was built in the canyon of Enguri river in West Georgia. It is located close to the Ingirishi active fault system, in a zone of high seismicity, intensity IX by MSK scale. The volume of the lake at Enguri dam is $10^{9}$ cubic meters and the high water level in the lake varies seasonally by $100 \mathrm{~m}$, which means that Enguri reservoir can activate reservoir-triggered seismicity (RTS). The dominant tectonic feature of the region is the active east-west-oriented Ingirishi fault, located to the north of the dam; its branch fault crosses the foundation of the Enguri dam [1]. 
Taking into account the high potential danger of the object, a geophysical monitoring system was organized even before construction works for providing secure exploitation of the large Enguri dam. Due to a high seismic activity of the region (Figure 1), the seismic station's network was installed in the area of Enguri dam also well before its construction, with the aim of studying possible reservoir-triggered activity [2]. The monitoring system of Enguri Dam and its foundation includes network of tiltmeters, piezometers, and reverse plumblines in the dam body [1], a weather station, water level gauge for monitoring water level in the lake, as well as a complex of strainmeters and tiltmeters, installed in the dam body and its foundation [3].

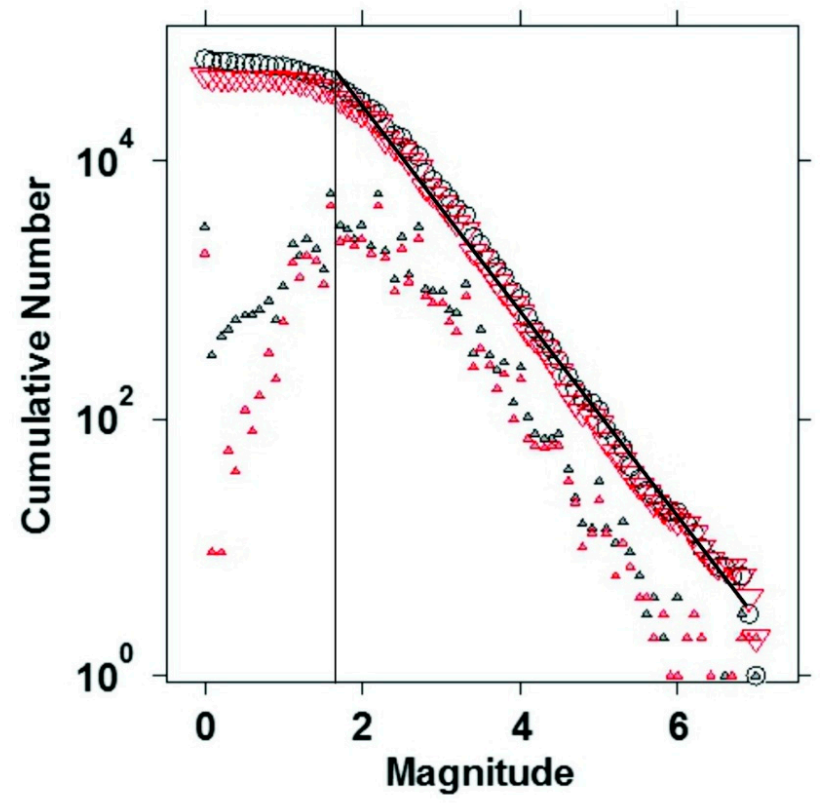

Figure 1. Cumulative Gutenberg-Richter plot of the whole (black circles) and aftershock-depleted (downward red triangles) catalogue of Georgia. The plot shows also the binned frequency-magnitude distribution of the whole (upward black triangles) and aftershock-depleted (upward red triangles) catalogues. The completeness magnitude is around M1.7.

The problem of human-induced earthquakes, including RTS, became a reality in the last decades [4-6]. The RTS pattern in the Enguri area should depend on the water level (WL) variation regime in the lake $[7,8]$. The main goal of the paper is to apply new methods of complexity analysis in order to assess, in a quantitative way, the correlation between WL variations and local seismicity and define the scale of man-made activity on the local (natural) seismicity pattern.

\section{Data}

The branch fault of the main Ingirishi fault crosses the foundation of Enguri dam, thus poses a hazard to its safety. In order to permanently monitor the fault behavior, two years before the first filling of the reservoir, in December 1974, a quartz strainmeter crossing the fault zone (FZ) was installed in the adit, located $100 \mathrm{~m}$ downstream from the foundation of the dam. The strainmeter's fixed and free parts are located on the intact rocks on the opposite sides of the FZ and are separated from this $10 \mathrm{~m}$ wide zone by a $5 \mathrm{~m}$ distance (the full length of the quartz tube is $22.5 \mathrm{~m}$ ). This means that the device records displacement of the intact blocks, divided by the fault zone in the normal to the fault plane direction, so it shows the fault zone's extension-contraction. The free end of the tube is equipped with a photo-optical recording system [3]. The displacements' sensitivity of this system is of the order of $0.18 \mu \mathrm{m} / \mathrm{mm}$, which allows also a tidal component of the fault zone strain to be recorded. At present, the laser system (Laser model R-39568, Green HeNe Laser, 633 nm and Laser Position Sensor OBP-A-9L) doubles the photo-optical registration. The laser is attached to the free end of the same quartz tube. Sensitivity of the strainmeter with the laser sensor is one $\mu \mathrm{m} / \mathrm{mm}$. 
The earthquake time series (ETS) for the Enguri area from 3 January 1974 to 31 December 2016 was compiled using catalogs from the Institute of Geophysics and International Seismological Centre. Our study area includes events located at the distances of 50 or $100 \mathrm{~km}$ from the lake. The completeness magnitude (CM) for the whole used catalog was around M 1.7 (Figure 1), but in some cases we confine ourselves by magnitude 2.2 for confidence, as in some periods the CM value increased to M2.2 due to non-stable functioning of the national seismic network.

In Figure 2 we present a spatial distribution of seismicity in the Enguri Dam region within $100 \mathrm{~km}$ distance from the dam with two magnitude gradations, from 0 to 5 and from 5 to 7 , as well as the scheme of active tectonic faults, according to [9].

$41^{\prime} 0 \mathrm{E} \quad 41^{\prime} 20 \mathrm{E} 41^{\prime} 40 \mathrm{E} 42^{\prime} 00 \mathrm{E} 42^{\prime} 20 \mathrm{E} 42^{\prime} 40 \mathrm{E} \quad 43^{\prime} 00 \mathrm{E}$

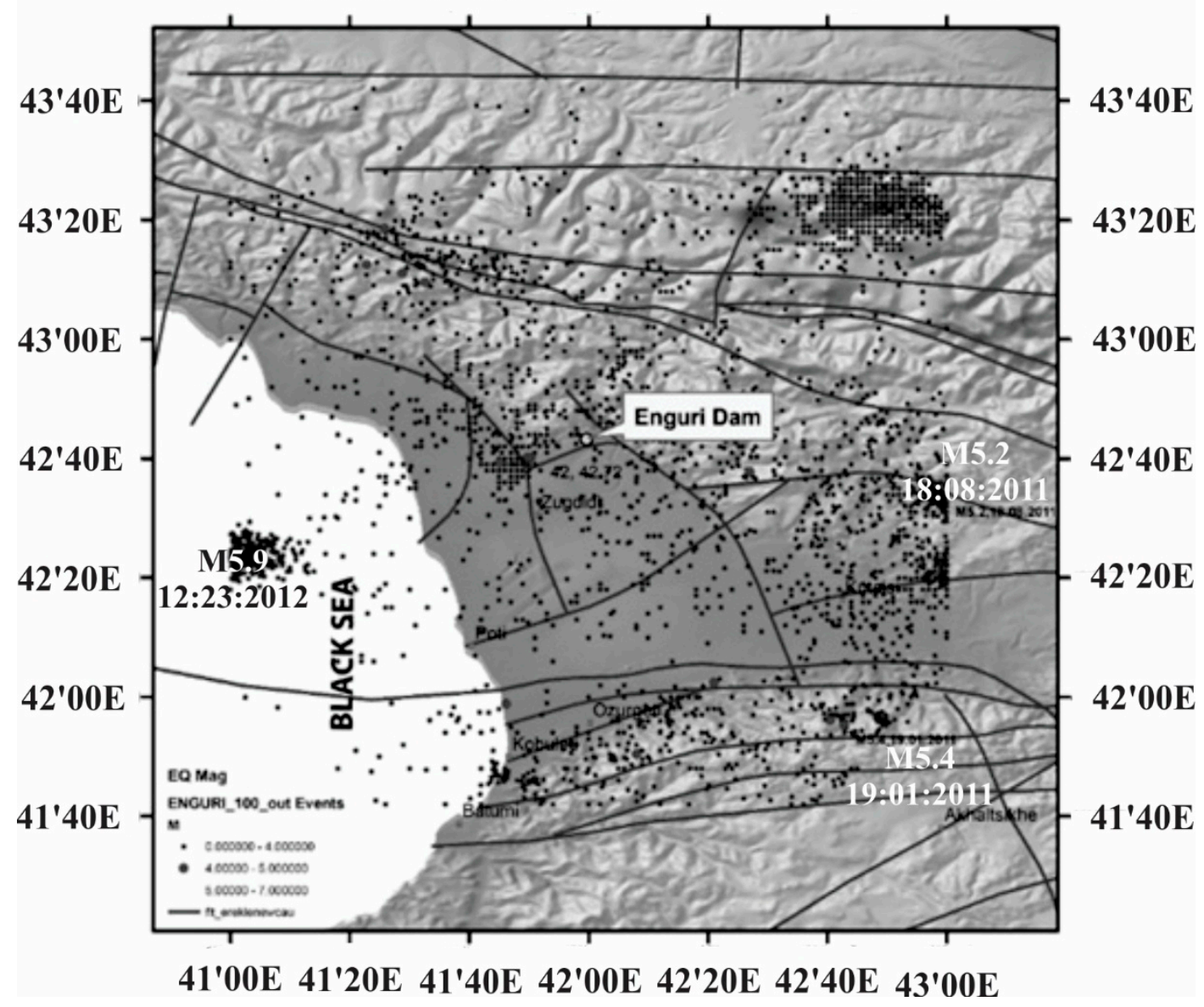

Figure 2. Seismicity of the Enguri Dam region within $100 \mathrm{~km}$ distance, with the scheme of active tectonic faults, according to [9].

Figure 3 shows almost 40 years' history of the area crossing the dam foundation fault zone extension-FZE-beginning from 1974 (i.e., FZE is the variation of the normal to the fault plane displacement of the free end of the strainmeter) and history of the dam foundation fault zone extension change in the Enguri reservoir $H$ beginning from April 1978. According to Figure 3, the dam area experiences stresses of different origin, acting on the different time scales, from decades to months and days. Actually, the object under study is a natural large-scale laboratory for investigation of geotectonic, man-made, and environmental impacts on the fault zone deformation. The summary contributions of these processes are reflected in the time series of fault zone strain. It is evident that the fault dynamics reflect the joint influence of two main factors: One leads to piecewise linear (in time) displacement (trend component) and the other one to quasiperiodic oscillations, decorating the main trend. 


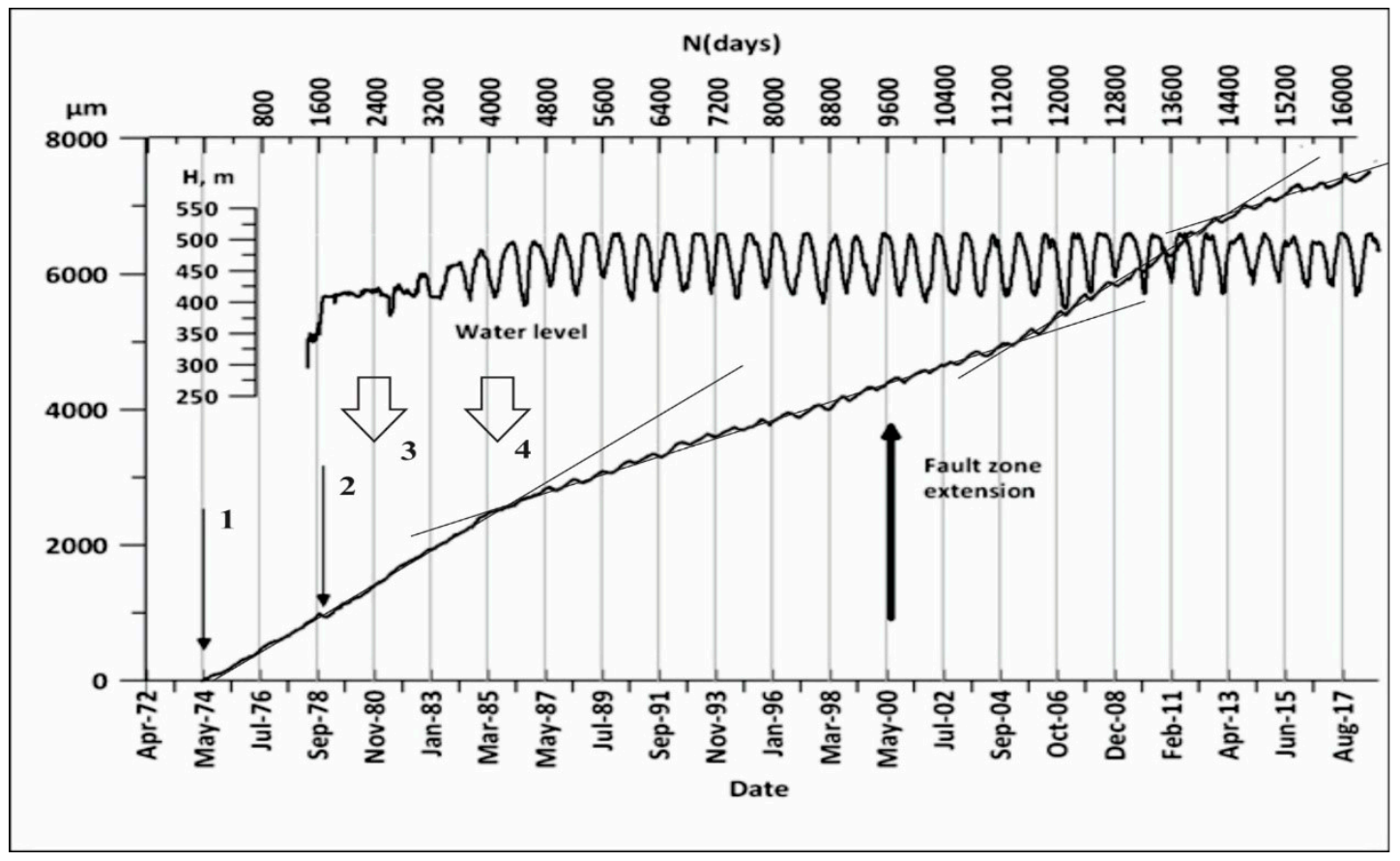

Figure 3. WL in the Enguri lake from 1978 (upper curve) to 2017 and the data on the extensioncompaction of the branch of a large Ingirishi fault, crossing the foundation of the dam from 1974 to 2017 (lower curve). Arrow 1 corresponds to the start (in 1974) of strainmeter monitoring four years before impounding, arrow 2 corresponds to the episode of the fault compaction by approximately $90 \mu \mathrm{m}$ due to WL rising fast by $100 \mathrm{~m}$ in 1978, arrows 3 and 4 show the moments of transitions in the nonlinear dynamics pattern of local seismicity (see Section 4 ). The upper horizontal axis shows the number of days after the start of strainmeter monitoring. Dashed straight lines mark periods of the fault's constant extension component slope.

The long-term piecewise linear trend documents persistent separation of fault faces (Figure 3), extending to $7000 \mu \mathrm{m}(7 \mathrm{~mm})$ during the observation period. The FZE rate $(y)$ depends on the time ( $t$ ) following a simple linear equation: $y(t)=a t-b$. where the coefficient $a$, the slope of the linear component of the FZE or the strain rate, differs from one period to another (Table 1). As the trend component with the same strain rate was recorded even before dam construction and lake filling, we attribute it to the long-term regional tectonic stress action.

At the same time, the fault zone extension rate (FZER) changes significantly with time, reflecting action of some non-stationary factors. In Table 1 we show the periodization of FZE behavior following the pattern of data evolution according to Figure 3, taking into consideration both components of strain-tectonic and anthropogenic. 
Table 1. Periodization of the fault zone extension.

\begin{tabular}{ccccc}
\hline $\begin{array}{c}\text { Number } \\
\text { of Periods }\end{array}$ & Periods & $\begin{array}{c}\text { Number of Days in the } \\
\text { Period; in Brackets the Same } \\
\text { from Day Zero (May 1974) to } \\
\text { the End of the Given Period }\end{array}$ & $\begin{array}{c}\text { Tectonic } \\
\text { Component of } \\
\text { Strain Rate } \boldsymbol{a} \\
\text { Microns/Year }\end{array}$ & $\begin{array}{c}\text { Pattern of Lake } \\
\text { Impounding Regime } \\
\text { (Man-Made } \\
\text { Component of Strain) }\end{array}$ \\
\hline 1 & May 1974-June 1978 & $1500(1500)$ & 250 & $\begin{array}{c}\text { Before lake } \\
\text { impounding }\end{array}$ \\
\hline 2 & June 1978-January 1981 & $1300(2800)$ & 235 & $\begin{array}{c}\text { WL in the lake raised } \\
\text { to 100 m }\end{array}$ \\
\hline 3 & January 1981-May 1985 & $1400(4200)$ & 235 & $\begin{array}{c}\text { Irregular quasi- } \\
\text { periodic regime }\end{array}$ \\
\hline 4 & May 1985-September 2004 & $7000(11,200)$ & 230 & $\begin{array}{c}\text { Regular quasi-periodic } \\
\text { regime } \\
\text { regime }\end{array}$ \\
\hline 5 & September 2004-February & $3200(14,400)$ & 150 & $\begin{array}{c}\text { Regular quasi-periodic } \\
\text { regime }\end{array}$ \\
\hline 6 & February 2013-March & $2000(16,400)$ & & \\
\hline
\end{tabular}

The most probable source of quasiperiodic changes in the FZE dynamics in Enguri area is the variation of the water load in the lake. We elucidate six periods with appreciable differences in the WL regime: (i) May 1974-June 1978, period before water fill, which we consider as a reference, (ii) April-January 1981 - the period of the initial filling of the reservoir; (iii) January 1981-May 1985the interval of initial irregular (quasiperiodic) variation of WL; (iv) May 1985-September 2004, in this period we observe a regular quasi-periodic load-unload regime, though the tectonic component of the strain rate varied in this period from 235 to 160 microns/year; (v) during September 2004February 2013 there is a regular quasi-periodic regime, but the tectonic component of the strain rate returns to the value 230 microns/year; (vi) in the interval February 2013-March 2018 a quasi-periodic component is decorating the tectonic strain rate of 150 microns/year.

General Characteristics of the test area seismicity. In Figure 4a we show the earthquake number per month from 1974 till 2017, and in Figure 4b we show the same on an extended time scale-from February 1976 till 1991 within $100 \mathrm{~km}$ distance from the dam. We also mark the magnitudes $\mathrm{M}$ and earthquakes (EQ's) separation from the dam $\Delta$ for the strongest events. According to Figure $5 \mathrm{~b}$ the strong seismic activity very close to the dam $(\Delta$ several $\mathrm{km})$ in December 1979 , with four events of magnitude M3.7-M4.3, follows the fast initial recharge of the lake to the critical for RTS initiation water level (100 m) in September 1978 (i.e., with a lag of 14 months).

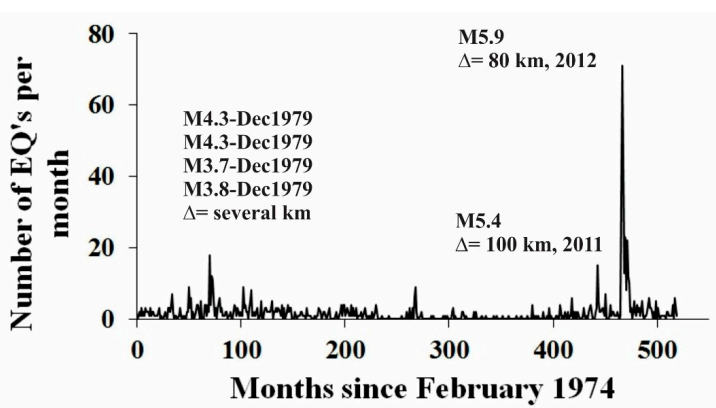

(a)

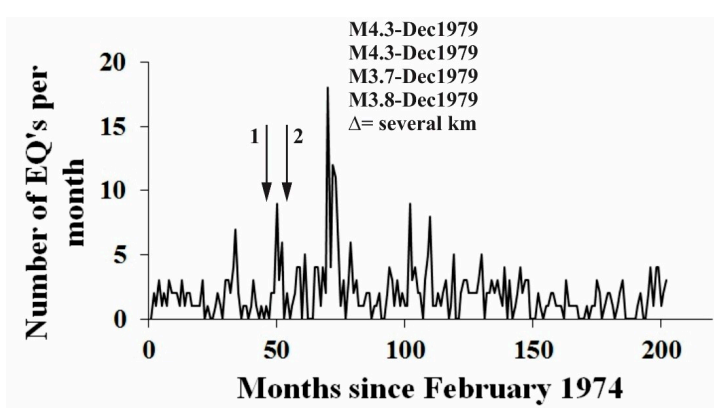

(b)

Figure 4. Number of EQs ( $\mathrm{M} \geq 2.2$ ) per month versus month number in the radius $100 \mathrm{~km}$ from the dam, $\Delta$ is the distance from the epicenter of a given EQ to the dam: (a) From February 1976 till 2017; (b) from February 1976 till 1991. Arrow marks 1 and 2 in Figure 5b correspond to 1) the beginning of filling, and 2) the WL rising to $100 \mathrm{~m}$ high. 


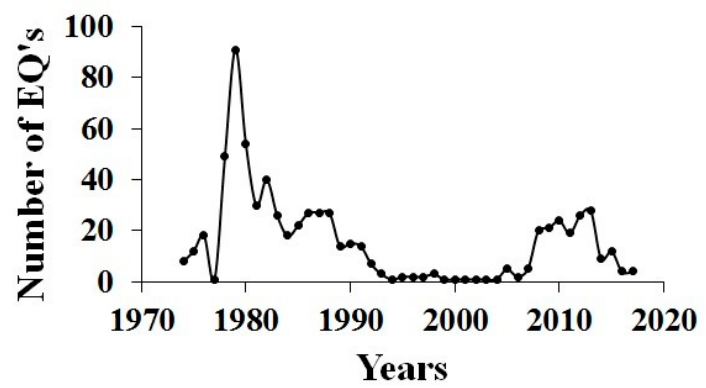

(a)

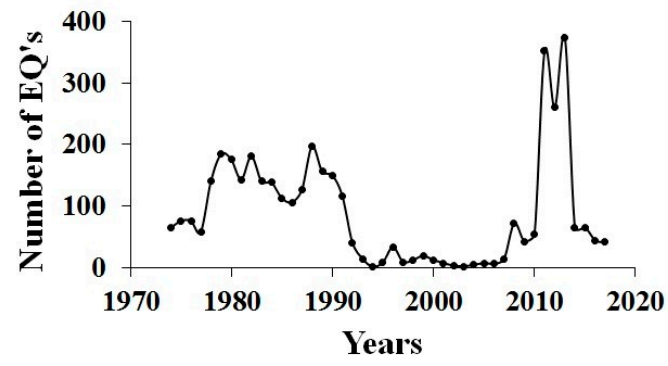

(b)

Figure 5. EQ number versus time in the near and larger zone: (a) EQ number-all events, including $M<2.2$ in the near zone, $R=50 \mathrm{~km}$; (b) EQ number-all events, including $M<2.2$ in the large zone, $\mathrm{R}=100 \mathrm{~km}$.

Figure 4a presents the number of events per month in the area with radiuses 50 and $100 \mathrm{~km}$ around Enguri dam, where several relatively strong EQs occur from 1974 to 2017. The epicenters of EQs M4.3 (21 December 1979), 4.3 (27 December 1979) are close to the Enguri lake and the EQs M5.4 (19 January 2011), M5.9 (23 December 2012), shown in Figures 2 and 4a, lay in the distance $80-100 \mathrm{~km}$.

To separate out more clearly the man-made impact, we present in Figure $4 \mathrm{~b}$ the detailed seismic rate during the first 200 months after January 1974. We present the corresponding water level regime in Figure 3: the recharge began in April 1978 (arrow 1) and WL abruptly rose to $100 \mathrm{~m}$ in November 1978 (arrow 2). Almost simultaneously the abrupt compaction of the fault zone crossing the foundation of dam by approximately $90 \mu \mathrm{m}$ was registered by the strainmeter installed on the fault (Figure 3). Almost a year later, in December 1979, series of EQs of magnitudes from 3.7 to 4.3 occurred close to the reservoir. These effects follow (with a year lag) the time of WL rising to the critical high of $100 \mathrm{~m}$, when, according to existing data $[5,7,8]$ the water load can generate reservoir-triggered seismicity (RTS).

In order to better resolve the seismic events related to filling and exploitation of the dam reservoir, we used the cellular approach [10], namely, we plotted separately the time sequences of all registered EQs (all EQs of magnitudes $M>1$ ) in the near to dam zone, in the radius $R=50 \mathrm{~km}$ from the dam, and in the larger area, in the radius $R=100 \mathrm{~km}$ (Figure 5b). In Figure 5 we show the same data for the EQs of magnitudes $M \geq 2$.2. Considering Figure 5, we can conclude that the EQ statistics in the near zone $\mathrm{R}=50 \mathrm{~km}$ (Figure $5 \mathrm{a}$ ) is dominated by events connected with reservoir impoundment and the swarm of EQs with $\Delta$ of the order of several $\mathrm{km}$ (compare with Figure $4 \mathrm{~b}$ ), when the major part of seismic activity in the larger zone $R=100 \mathrm{~km}$ (Figure $5 \mathrm{~b}$ ) is due to the relatively strong remote events of magnitude M5.2-5.9 with $\Delta$ of the order of $80-100 \mathrm{~km}$, which are too far from Enguri dam and belong to the class of regional tectonic events (see Figures 2 and $3 b$ ). It follows that, in order to distinguish RIS events, it is better to analyze the seismic catalog in the near zone ( $R=50 \mathrm{~km})$, where seismic events dominate, located close to Enguri dam. This restriction does not work for analysis of complexity, especially when we analyze waiting times of EQ, because RIS is characterized by a quasiperiodic recurrence property due to regularity of reservoir load-unload. In turn it means that the role of random seismic events when studying regularity in waiting times, even at the distance $100 \mathrm{~km}$, is relatively small.

\section{Methodology}

The earthquake time series (ETS) presented in Figure 4a,b presents a complex mix of background seismicity, characteristic for the seismotectonics of the test area with a seismic response to the lake impoundment and, further, to WL quasiperiodic regulation. To single out the dynamical patterns of the seismic data sets connected with WL variation, we used new effective methods of complexity analysis [11] applied to magnitudes and waiting times of earthquake time series (ETS). The 
complexity analysis allow recognition of periods with different levels of ordering/determinism, which we connect with transition in WL regime from disordered (1978-1984) to more ordered (1985-1986) and finally, to quasi-periodic loading (1986 until now). We give a short description of these methods below.

Earlier several studies were devoted to complexity analysis of seismic regime in the Enguri dam area, namely to variation of the phase diffusion coefficient of phase differences between daily released seismic energy and water level daily variations [12,13], Visibility Graph Analysis [14], and Singular Spectrum Analysis [15]. In the present paper we analyze recurrent patterns of local seismicity, using such methods as recurrence plots, detrended fluctuation analysis, and Lempel and Ziv complexity measure.

Recurrence Plots (RP). Recurrence Plots allow visualization of the recurrent behavior of a dynamical system by plotting the arbitrary close (after some time lag) states in the two-dimensional projection of the high-dimensional phase space trajectory $[16,17]$. The recurrence of the same state after some time lag is plotted on the square matrix, where both axes represent time, by zeros and ones or by differently colored dots. The time lag between recurrent points $i$ and $j$ of the trajectory is defined as the threshold time interval (threshold distance) $\varepsilon_{i}$. The RP revealed some structural patterns, which are different for different degrees of determinism in the phase space of the system.

Detrended Fluctuation Analysis (DFA). Long-range time correlations in the investigated data sets were assessed by the method of detrended fluctuation analysis (DFA) [18,19]. Method of DFA permits the detection of long-range correlations embedded in a nonstationary time series through calculation of a quantitative parameter-DFA scaling exponent. This analysis technique is widely accepted and often used for different types of time series including geophysical data sets [14,15].

The basics of DFA are well known and described in series of often cited articles, so we will just briefly discuss its main steps. At first, a given time series of $N$ samples is integrated. After, the integrated time series is divided into boxes of length $n$, and in each box the polynomial local trend is calculated and removed. Then $N / n$ mean squared residuals-detrended fluctuation functions $(F(n))$ - should be calculated for each box of size $n$.

$$
F(n)=\sqrt{\frac{1}{N}} \sum_{i=1}^{N}\left[Y(i)-Y_{n}(i)\right]^{2} .
$$

Since $F(n)$ increases with the box size $n$, in case of fractal or self-similar properties of analyzed data, a power-law behavior $F(n) \sim n^{\alpha}$ can be revealed. If a power law scaling exists, the $F(n)$ vs. $n$ relationship, in a double logarithmic fluctuation plot, will be linear or close to linear and the scaling exponent $\alpha$ can be estimated. If the scaling exponent $\alpha=0.5$, we deal with the uncorrelated dynamics of random walk type (Peng et al. 1994; Liu et al. 1999). In this case, the time series is identical to white noise. If $\alpha$ is different from 0.5 , then the time series is regarded as long-range correlated or anticorrelated, with $\alpha>0.5$ or $\alpha<0.5$ accordingly [18,19]. The scaling exponent $\alpha$ is considered as an indicator of the nature of the fluctuations giving the information about the long-range power law correlation properties in the analyzed data sets. DFA can be accomplished for different orders of the polynomial fitting in order to eliminate trends of certain origin.

Recurrent quantification analysis. In order to further quantify changes in dynamical structure of analyzed data sets, we used the Recurrence Quantification Analysis (RQA) approach [17,20,21]. In general, RQA is a quantitative extension of the recurrent plot (RP) construction method, which is based on the fact that returns (recurrence) to the certain system condition or state space location is a fundamental property of any dynamical system with quantifiable extent of determinism in underlying laws [16]. In order for RQA calculations to be successfully fulfilled, at first the phase space trajectory should be reconstructed from the given scalar data sets, the proximity of points of the phase trajectory should be tested and marked by the condition that the distance between them is less than a specified threshold [16]. In this way, a two-dimensional representation of the recurrence features of dynamics embedded in high-dimensional phase space can be obtained. Then small-scale structure of recurrence plots can be quantified [20-24]. RQA technique quantifies visual features in a $N \times N$ 
distance matrix recurrence plot and defines several measures of complexity. Exactly, RQA provides several measures of complexity based on the quantification of diagonally- and vertically-oriented lines in the recurrence plot. In this research, we present one of such measures (\%determinism), which often is used to reveal changes in the extent of regularity in analyzed data sets.

Lempel and Ziv complexity measure. The Lempel and Ziv algorithmic complexity (LZC) calculation $[25,26]$ is another often used method for quantification of the extent of order in analyzed data sets of different origin. LZC is based on the transformation of a given data sequence into a new symbolic sequence. For this original data are converted into a $(0,1)$ sequence by comparing them to a certain threshold value (usually median of the original data set). Once the symbolic sequence is obtained, it is parsed to obtain distinct words, and the words are encoded. Denoting the length of the encoded sequence for those words, the LZ complexity can be defined as

$$
C_{L Z}=\frac{L(n)}{n},
$$

where $L(n)$ is the length of the encoded sequence and $n$ is the total length of sequence [26]. Parsing methods can be different [26,27]. In this work, we used the scheme described in [27]. Data sequences with a certain regularity are less complex, and the LZ complexity increases as the sequence grows in length and irregularity. In our case, the sequence length is constant and LZC depends only on the level of regularity.

\section{Results}

Results of Complexity analysis. In this study, we analyzed two types of ETS related to the seismicity of Enguri area: The waiting times and the magnitude sequences to study the changes possibly linked with dynamical changes in the RTS characteristics of the investigated seismic area related with the loading regime of the dam.

As we mentioned earlier, though the number of events in the far zone can be spoiled by the EQs, not related to the reservoir-induced strain, the waiting times (WTs) distribution is less sensitive to (background) random events, even those relatively far from the dam (e.g., for $\mathrm{R}=100 \mathrm{~km}$ ).

Results for the near zone $R=50 \mathrm{~km}$. In this case (for $\mathrm{R}=50 \mathrm{~km}$ ), we included into complexity analysis, namely RP, namely the Visual Recurrence Analysis methods [28] and DFA methods, EQs below representative magnitude in order to fulfill the condition of used methods - to have at least 500 events. The distinct transitions from a less regular to more regular pattern in seismic regime occurred in 1985 to 1986 (a), when the WL change in reservoir became quasiperiodic (i.e., at the day mark 2000 in Figure 6b, which corresponds to the year 1985 (b); see also Figure 3). Note the light yellow diagonal lines in (a) after 1986, which is a mark of quasi-periodicity in RIS. Similarly, the DFA analysis (Figure 6c) points to the beginning of ordering in seismic events after 1980 and the transition to strong recurrence regime after 1986.

Results for M2.2 the far zone $R=100 \mathrm{~km}$. We used DFA, RP, RQA, and LZC methods for analysis of interevent times and magnitude data sequences from the Enguri seismic catalogue (1974-2017) involving 913 events above M2.2 that occurred within $100 \mathrm{~km}$ distance from the dam.

In Figure 7 , we present results of DFA exponent $\alpha$ calculation of waiting time sequences. Calculation was done for 500 data length windows shifted by one data. DFA exponents for interevent times (Figure 7) indicate a gradual DFA exponent increase toward the period of reservoir water level periodic variation. A stronger increase took place in the period starting from 1984 and lasts till 2017. According to these results under the influence of water level periodic variation in the reservoir, long-range correlation clearly increased in the time distribution of earthquakes, while the magnitude distribution of earthquakes is characterized by slight or negligible changes in long-range features just at the beginning of observation period and after the 200th window. The DFA for the magnitude distribution of earthquakes is characterized by slight or negligible changes in long-range features. 


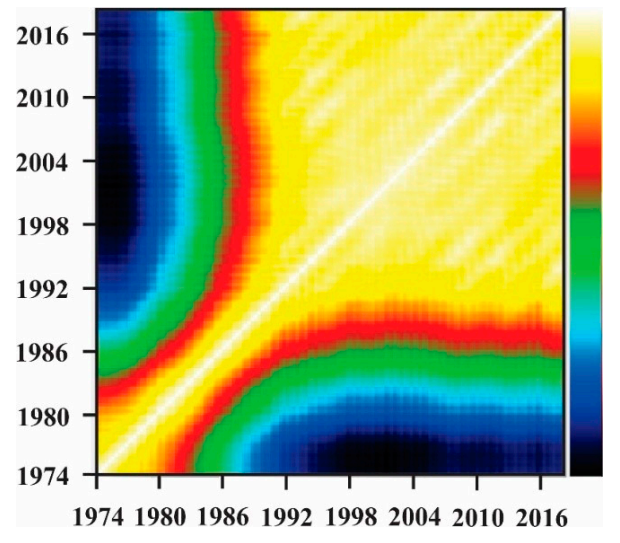

(a)

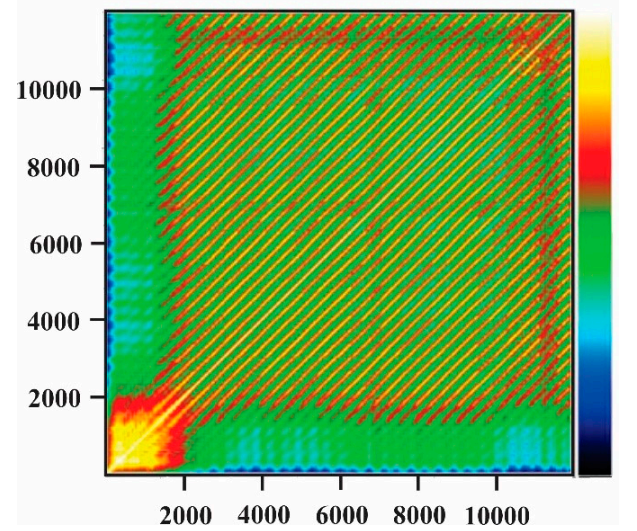

(b)

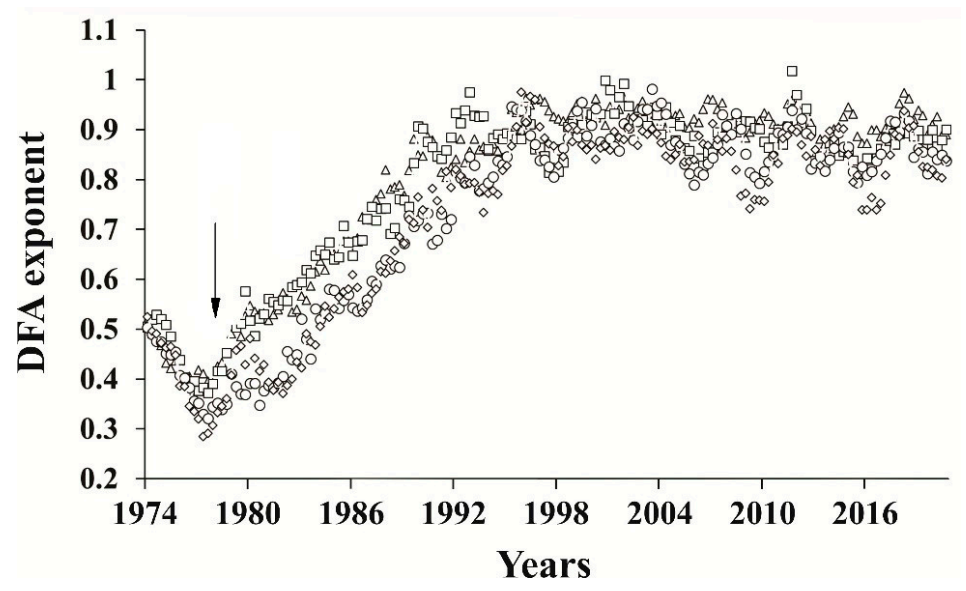

(c)

Figure 6. Recurrence plots of waiting times of EQs in local seismicity from March 1974 to March 2017 for $\mathrm{R}=50 \mathrm{~km}$ (a) and water level in the Enguri dam reservoir from April 1978 to August 2017 (b), where on the axes are day marks after the start of recharge. The blue cells correspond to less recurrence and yellow ones to better recurrence of events; (c) the DFA analysis reveals beginning of ordering in seismic events after 1980 and strong recurrence regime after 1986.

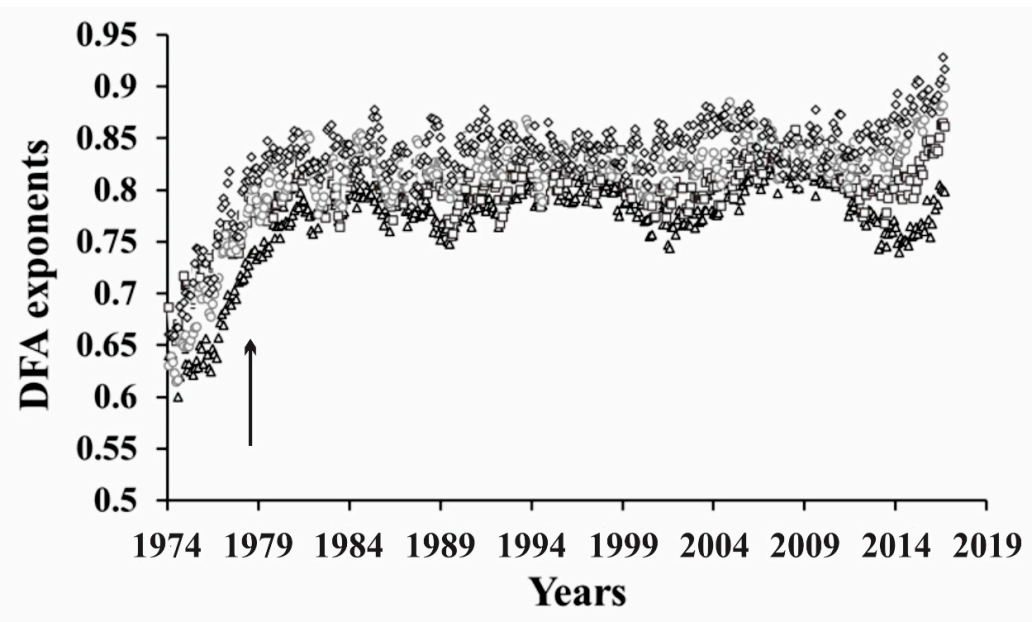

Figure 7. DFA exponents of waiting times sequences (M2.2 threshold) around the Enguri reservoir $(100 \mathrm{~km}$ ) 1974-2017. Polynomial fit from 2 to 5. (Triangles $\mathrm{p}=2$, squares $\mathrm{p}=3$, circles $\mathrm{p}=4$, diamonds $p=5$ ). Arrow marks the beginning of lake recharge; long-range correlation increases after 1984 . 
We also applied RQA and LZC methods to waiting times and magnitude data sequences from the Enguri seismic catalogue (1974-2017). Calculation was done for 500 data length windows shifted by one data (Figures $8-10$ ).

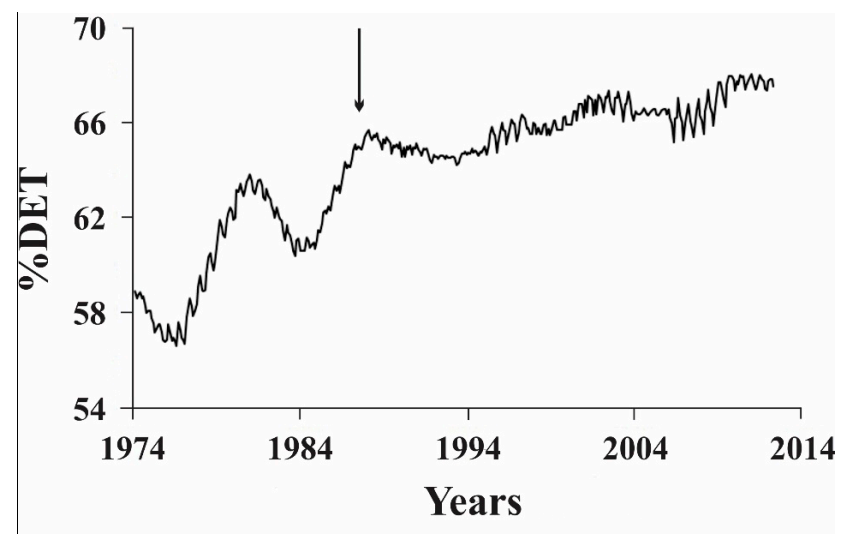

Figure 8. \%DET of magnitude data sequences (M2.2 threshold) around the Enguri reservoir $(\mathrm{R}=100 \mathrm{~km})$ 1974-2017. Note increased determinism in waiting times after 1986.

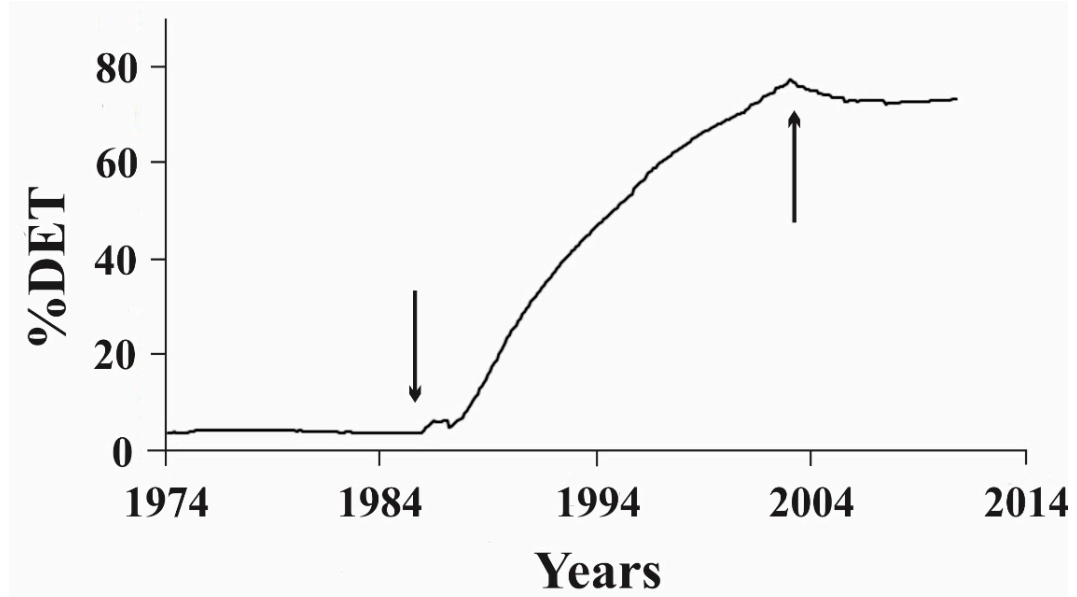

Figure 9. \%DET of interevent times sequences (M2.2 threshold) around the Enguri reservoir $(\mathrm{R}=100 \mathrm{~km})$ 1974-2017. Note increased determinism in waiting times after 1986.

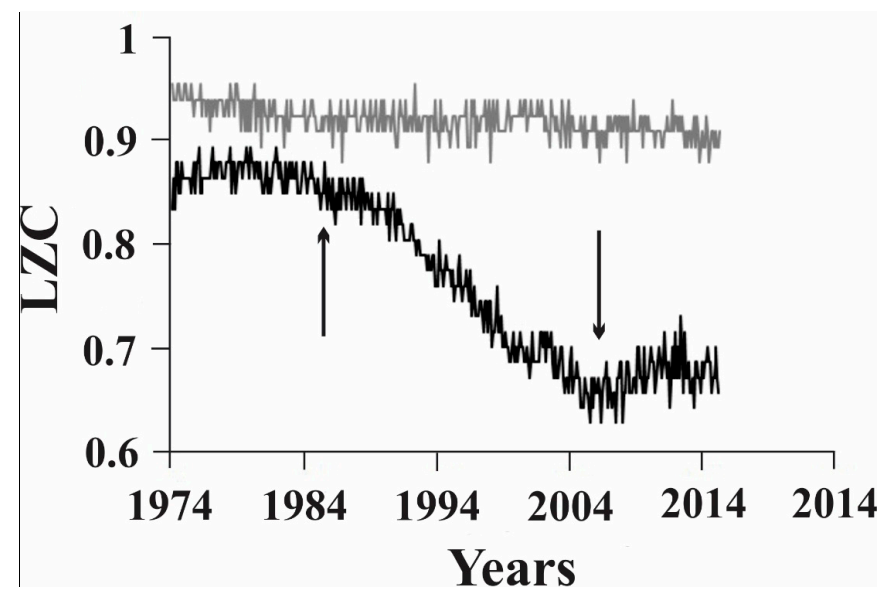

Figure 10. Lempel and Ziv complexity measure calculated for (M2.2 threshold) around the Enguri reservoir $(\mathrm{R}=100 \mathrm{~km})$ 1974-2017 using 500 data windows shifted by one data. Magnitudes sequence (grey) and interevent sequence (black). 


\section{Discussion: Nonlinear Dynamics Patterns in Seismicity and Water Level Variations in Enguri Lake}

Let us consider results, obtained by different complexity analysis approaches: The methods abbreviation with a subscript $m$ for magnitude time series and by a subscript $w t$ for the waiting times, for example, (RQA) $m$ and (RQA) $w$.

- We can elucidate the transition in seismic regime by the intensive increase of the exponent for the waiting times (DFA) $w$ after 1984.

- $\quad$ Using the RQA approach, we reveal drastic changes in ETS dynamics for (\%DET) $m$ after 1986 and for (\%DET) wt around 1986 and 2004, when the waiting times became maximal and stable.

- Using LZC, we see that there are no changes in (LZC) $m$, but (LZC)wt undergoes drastic changes in waiting times dynamics around 1986 and 2004.

Resuming, we can mark the dates of significant changes in the seismic time series dynamics around 1986 and in 2004 by both RQA and LZC methods.

Results of calculations presented in Figures 6-10 convinces us that the changes that occurred in waiting times data sets are much stronger than in magnitude sequences. At the same time \%DET of the waiting times sequence essentially increases and LZC noticeably decreases: Both these effects point to the growth of order (recurrence) in ETS in the period 1985-1986. According to these results under influence of water level periodic variation in reservoir, long-range correlation clearly increased in earthquakes time distribution, while earthquakes magnitude distribution is characterized by slight or negligible change in long-range features.

Comparing dates of WL regime change and fault zone deformation patterns with transitions in the ETS dynamics, we can conclude that the transition in RQA and LZC in the period 1984-1986 is connected with the beginning of the quasiperiodic load-unload process of the reservoir (see Figure 3). Note, that from 1985 to 1986 the strain in the fault zone under the Enguri Dam also reveals quasi-periodic decoration of the summary strain line (Figure 3).

Thus, in the last period, beginning from the period 1985-1986, the dynamics of local seismicity, especially, waiting times is much more ordered due probably to synchronization of seismic activity with the regular pattern of WL variation. This conclusion is confirmed by our earlier work where we carried out analysis of Enguri area seismic activity using the singular spectrum analysis (SSA) technique in order to investigate the relationship of local seismicity with the reservoir water variations [12-15]. We revealed the dominant one-year period in seismicity, which corresponds to seasonal load-unload of the Enguri dam lake; this period was absent in ETS of the area in the reference period before lake impoundment.

\section{Conclusions}

On the basis of the recurrent plots, recurrent quantification analysis, and Lempel-Ziv complexity analysis carried out on interevent and magnitude sequences of the Enguri area seismic catalogue, we conclude that influence of water level periodic variation makes time distribution of local earthquakes more regular (synchronized with water level variation), compared to the period without such weak periodic influences. This means that nonlinear dynamics methods are effective in detection and quantitative analysis of reservoir-induced seismicity near large dams, as they make it possible to divide events, ordered by the impact of reservoir water regular strain from the background seismicity.

Acknowledgments: Authors acknowledge the financial support of the Open Partial Agreement on the Major Disasters at the Council of Europe (Ref. No.: GA/2017/08, FIMS PO No.: 537534) and Shota Rustaveli National Science Foundation of Georgia (Project No.: 216732). We have not received funds for covering the costs to publish in open access.

Author Contributions: V.A. and T.C. conceived and designed the experiments; V.A. and N.D. performed the experiments; T.C., T.M., L.C. and E.M. analyzed the data; T.M. contributed analysis tools; T.C. and T.M. wrote the paper. 
Conflicts of Interest: The authors declare no conflicts of interest.

\section{References}

1. Chelidze, T.; Matcharashvili, T.; Abashidze, V.; Kalabegishvili, M.; Zhukova, N. Real time monitoring for analysis of dam stability: Potential of nonlinear elasticity and nonlinear dynamics approaches. Front. Struct. Civ. Eng. 2013, 7, 188-205.

2. Balavadze, B. (Ed.) Geological-Geophysical Studies in the Region of Enguri Hydro Power Station; Metsniereba: Tbilisi, Georgia, 1981. (In Russian)

3. Abashidze, V. Geophysical Monitoring of Geodynamical Processes at Enguri Dam. Publishing House 11.

4. Grigoli, F.; Cesca, S.; Priolo, E.; Rinaldi, A.P.; Clinton, J.F.; Stabile, T.A.; Dost, B.; Fernandez, M.G.; Wiemer, S.; Dahm, T. Current challenges in monitoring, discrimination, and management of induced seismicity related to underground industrial activities: A European perspective. Rev. Geophys. 2017, 55, 310-340.

5. Foulger G.; Miles P.; Wilson M.; Gluyas, J.; Juliana, B.; Davies, R. Global review of human-induced earthquakes. Earth-Sci. Rev. 2017, doi:10.1016/j.earscirev.2017.07.008.

6. Savage, H.M.; Kirkpatrick, J.D.; Mori, J.J.; Brodsky, E.E.; Ellsworth, W.L.; Carpenter, B.M.; Chen, X.; Cappa, F.; Kano, Y. Scientific Exploration of Induced SeisMicity and Stress (SEISMS). Sci. Drill. 2017, 23, 57-63.

7. Gupta, H.K. Reservoir-Induced Earthquakes; Elsevier: Amsterdam, The Netherlands, 1992.

8. Gupta H.K. Review: Reservoir Triggered Seismicity (RTS) at Koyna, India, over the Past 50 Yrs. Bull. Seismol. Soc. Am. 2018, 108, 2907-2918, doi:10.1785/0120180019.

9. Gamkrelidze, I.; Giorgobiani, T.; Kuloshvili, S.; Lobzhanidze, G.; Shengelaia, G. Active Deep Faults Map and Catalogue for the Territory of Georgia. Bull. Georgian Acad. Sci. 1998, 157, 80-85.

10. Kafka, A.L.; Ebel, J.E. Proximity to Past Earthquakes as a Least-Astonishing Hypothesis for Forecasting Locations of Future Earthquakes. Bull. Seism. Soc. Am. 2011, 101, 1618-1629.

11. Chelidze, T.; Valliantos, F.; Telesca, L. (Eds.) Complexity of Seismic Time Series: Measurement and Applications; Elsevier: Amsterdam, The Netherlands, 2018.

12. Matcharashvili, T.; Chelidze, T.; Peinke, J. Increase of order in seismic processes around reservoir-induced by water level periodic variation. Nonlin. Dyn. 2008, 51, 399-407.

13. Matcharashvili, T.; Chelidze, T.; Abashidze, V.; Zhukova, N.; Meparidze, E. Changes in Dynamics of Seismic Processes Around Enguri High Dam Reservoir Induced by Periodic Variation of Water Level. In Stochastic Flood Forecasting System; Springer Science and Business Media LLC: Berlin/Heidelberg, Germany, 2010; Volume 1, pp. 273-286.

14. Telesca, L.; Chelidze, T. Visibility Graph Analysis of Seismicity around Enguri High Arch Dam, Caucasus. Bull. Seism. Soc. Am. 2018, 108, 3141-3147.

15. Telesca, L.; Matcharasvili, T.; Chelidze, T.; Zhukova, N. Relationship between seismicity and water level in the Enguri high dam area (Georgia) using the singular spectrum analysis. Nat. Hazards Earth Syst. Sci. 2012, 12, 2479-2485.

16. Eckmann, J.-P.; Kamphorst, S.O; Ruelle, D. Recurrence Plots of Dynamical Systems. EPL Europhys. Lett. 1987, 4, 973-977.

17. Webber, C.; Marwan, N. (Eds.) Recurrence Quantification Analysis: Theory and Best Practices; Springer Cham, Switzerland; Heidelberg, Germany, 2015.

18. Peng, C.-K.; Buldyrev, S.; Havlin, S.; Simons, M.; Stanley, H.E.; Goldberger, A.L. Mosaic organization of DNA nucleotides. Phys. Rev. E 1994, 49, 1685-1689.

19. Peng, C.-K.; Havlin, S.; Stanley, H.E.; Goldberger, A.L. Quantification of scaling exponents and crossover phenomena in nonstationary heartbeat time series. Chaos: Interdiscip. J. Nonlinear Sci. 1995, 5, 82-87.

20. Zbilut, J.P.; Webber, C.L. Embeddings and delays as derived from quantification of recurrence plots. Phys. Lett. A 1992, 171, 199-203.

21. Webber, C.L.; Zbilut, J.P. Dynamical assessment of physiological systems and states using recurrence plot strategies. J. Appl. Physiol. 1994, 76, 965-973.

22. Webber, C.L.; Zbilut, J.P. Recurrence quantification analysis of nonlinear dynamical systems. In Tutorials in Contemporary Nonlinear Methods for the Behavioral Sciences; Riley, M.A., Van Orden, G.C., Eds.; National Science Foundation: Arlington, VA, USA, 2005; pp. 26-94. 
23. Marwan, N.; Romano, M.C.; Thiel, M.; Kurths, J. Recurrence plots for the analysis of complex systems. Phys. Rep. 2007, 438, 237-329.

24. Webber, C.L.; Marwan, N.; Facchini, A.; Giuliani, A. Simpler methods do it better: Success of Recurrence Quantification Analysis as a general purpose data analysis tool. Phys. Lett. A 2009, 373, 3753-3756.

25. Lempel, A.; Ziv, J. On the complexity of finite sequences. IEEE Trans. Inf. Theory 1976, 22, 75-81.

26. Hu, J.; Gao, J.; Principe, J.C. Analysis of Biomedical Signals by the Lempel-Ziv Complexity: The Effect of Finite Data Size. IEEE Trans. Biomed. Eng. 2006, 53, 2606-2609.

27. Cover, T.; Thomas, J. Elements of Information Theory; Wiley: New York, NY, USA, 1991.

28. Kononov, E. Visual Recurrence Analysis 4.9. Available online: https://visual-recurrenceanalysis.software.informer.com/4.9/ (accessed on 25 December 2019).

(C) 2019 by the authors. Licensee MDPI, Basel, Switzerland. This article is an open access article distributed under the terms and conditions of the Creative Commons Attribution (CC BY) license (http://creativecommons.org/licenses/by/4.0/). 